\title{
CUIDADOS COM ESTRUTURAS DE CONCRETO EM SITUAÇÃO DE INCÊNDIO
}

\author{
CARE OF CONCRETE STRUCTURES IN A FIRE SITUATION
}

\author{
Everton Breno dos Santos de Oliveira ${ }^{1}$ \\ Lucas Rodrigo Miranda ${ }^{2}$
}

https://doi.org/10.47820/recima21.v2i10.934

\begin{abstract}
Resumo: O estudo tem o intuito de apresentar cuidados a serem tomados com estruturas de concreto em situação de incêndio, informando a todos os interessados as normas técnicas de seguimento e concepção do projeto que devem seguidas na fase de preparação das estruturas, em seguida devem ser observados os elementos para a análise da estrutura após o incêndio e os materiais que contribuem no retardo do colapso da estrutura, caso a mesma seja exposta a um incêndio, garantindo assim toda integridade da vida humana, da própria estrutura e das edificações localizadas no entorno da estrutura.
\end{abstract}

Palavras-chave: Estruturas de concreto, normas, incêndio.

Abstract: The study aims to present the precautions to be taken with concrete structures in a fire situation, informing all interested parties of the technical standards for monitoring and designing the project that must be followed in the preparation phase of the structures, and then the elements for the analysis of the structure after the fire and the materials that contribute to delay the structure's collapse, in case it is exposed to a fire, thus guaranteeing the entire integrity of human life, of the structure itself and of the buildings located around the structure.

Key-words: Concrete structures, standards, fire.

\footnotetext{
${ }^{1}$ Graduando do Curso de Engenharia Civil da Universidade de Araraquara- UNIARA. Araraquara-SP. E-mail: ton.breno@hotmail.com

${ }^{2}$ Orientador. Docente Curso de Engenharia Civil da Universidade de Araraquara- UNIARA. Araraquara-SP. Email:1miranda@uniara.edu.br
} 


\section{INTRODUÇÃO}

Os primeiros registos de sistemas de combate a incêndio, era contemplado por vigias que ficavam rondando a cidade, e no primeiro contato com incêndios na cidade, os vigias alertavam os cidadãos, para que esses ficassem ciente da catástrofe e pudessem evacuar a cidade. Porém este é um método falho, e com isso continuaram a ocorrer vários incêndios registrados pela humanidade, e com isso surge a demanda de aprimorar os sistemas de combate a incêndio. (SOUSA, 2015).

O primeiro manual contra incêndio, no Estados Unidos, surgiu em 1896. Era um livro com conselhos para a prevenção e extinção de incêndios e tinha como objetivo promover o trabalho dos inspetores de seguradoras. Antes de ocorrer um incêndio com número alto de perdas de vida humana, o foco da segurança contra incêndio é a proteção da propriedade. Depois de quatro grandes incêndios que causaram centenas de vítimas, a situação mudou: o lloquis Theatre de Chicago em 1903, a Opera Rhoads em Boyertown em 1908, a Lakeview Elementary School em Cleveland em 1908 e a Triangle Shirt Company em Nova York em 1911. Após esses desastres, foi publicada a quinta edição do Manual de Proteção contra Incêndio, considerado um marco pela National Fire Protection Association (NFPA) em 1914, sua principal missão era proteger vidas, não apenas propriedades. A NFPA também estabeleceu um Comitê de Segurança da Vida, que sequêncialmente fez recomendações sobre a construção de escadas e saídas de emergência em fábricas, escolas etc. Essas recomendações ainda estão presentes na base do código. (SILVA, 2012 / SOUSA, 2015).

$\mathrm{Na}$ década de 1970, o Brasil era muito semelhante aos Estados Unidos em termos de segurança contra incêndios. No entanto, não há registros de incêndios que causaram perdas significativas de vidas em terras em todo o país. Antes, as normas brasileiras da época eram voltadas principalmente para a produção de extintores de incêndio. No entanto, uma série de tragédias mudaram a situação no Brasil em termos de proteção e proteção contra incêndio, sendo a principal tragédia o incêndio no GranCirco Norte Americano em Niterói em 1961 - a maior perda de vidas - o incêndio em Andraus em 1972. Edifícios em São Paulo - foi o primeiro grande incêndio em um prédio alto - e o incêndio no prédio Joelma, em São Paulo, em 1974. A catástrofe no edifício Joelma causou grande impacto, pois várias pessoas pulavam do alto do edifício gerando fortes imagens, e com repercussão até atualmente. Porém, após a análise feita no edifício certificou-se que ele estaria dentro das normas vigentes da época. (SOUSA, 2015).

Após essas tragédias, os responsáveis perceberam a demanda de aprimorar os padrões atuais no país, pois um relatório do Instituto Paulista de Engenharia forneceu um relatório que provou que o Edifício Joelma atendia aos padrões vigentes na época. Em 1983, o Estado de São Paulo promulgou o Decreto no 20.811 (São Paulo, 1983). Finalmente a lei foi promulgada em 2011. São 44 regulamentos técnicos no total, que possuem requisitos de divisão de áreas, desagregação de edifícios, monitoramento de materiais, inspeção de fumaça, saídas de emergência, chuveiros automáticos e segurança estrutural. O objetivo dos regulamentos modernos de segurança contra incêndio trata de proteger vidas e evitar que incêndios (se ocorrerem) se espalhem para além dos compartimentos do edifício. A segurança da vida depende da rápida evacuação do ambiente em chamas, pois a principal causa de morte em um incêndio é a exposição à fumaça no primeiro momento do acidente. 
As medidas de combate e extinção de incêndio que permitem a evacuação rápida do ambiente de combustão devem ser analisadas pelo projetista em conjunto com o projetista. O proprietário também considera as condições específicas da obra, como o tamanho do prédio, a quantidade de pessoas e a finalidade. (SOUSA, 2015).

Conforme a definição da NBR 14432 (ABNT, 2001), proteção ativa refere-se ao tipo de proteção contra incêndio que é acionada manual ou automaticamente em resposta ao estímulo causado pelo incêndio. De acordo com o Decreto no 56.819 (São Paulo, 2011), todos os edifícios residenciais de vários andares, escolas, escritórios e hotéis devem formar brigadas de incêndio. A proteção passiva é definida como um conjunto de medidas incorporadas ao sistema construtivo do edifício desempenha um papel na utilização do edifício, reage passivamente em caso de incêndio e não cria condições para a propagação e desenvolvimento do incêndio. A proteção passiva garante proteção contra incêndio, que é conveniente para os usuários escaparem, se aproximarem e entrarem em edifícios para operações de combate. Exemplos de proteção passiva são a compartimentação horizontal ou vertical, Resistência ao fogo de vias de escape e estruturas. (SOUSA, 2015).

A compartimentação é um dos principais métodos de segurança contra incêndio. Um compartimento é um edifício ou parte de um edifício, que inclui uma ou mais divisões, espaços ou pisos, e tem por objetivo evitar que o fogo se alastre dentro do próprio edifício e passe o incêndio para os edifícios próximos. A compartimentação é separada em compartimentos horizontais e verticais. $O$ primeiro impede a propagação horizontal e o segundo impede a propagação vertical. A resistência ao fogo é a propriedade dos elementos de construção de resistir ao fogo, manter a sua segurança estrutural, estanqueidade e isolamento. $O$ tempo requerido de resistência ao fogo (TRRF) em cada caso é fornecido pelas instruções técnicas dos bombeiros estaduais. Edifícios pequenos são fáceis de desocupar, requerem menos dispositivos de segurança contra incêndio e podem não exigir verificação. (SOUSA, 2015).

Em relação ao dimensionamento das estruturas em situação de incêndio, temos as normas NBR 14323:1999 para estruturas de aço (ABNT, 1999) e NBR 15200:2012 para estruturas de concreto (ABNT, 2012). Em diversos estados estas normas devem ser adotadas por decreto estadual, e nos estados onde não há esta exigência deve-se considerar o Código do Consumidor (CDC), que requer cumprimento das normas ABNT. E para complementar temos as normas técnicas e instruções técnicas do corpo de bombeiros, no Estado de São Paulo por exemplo, temos a "Norma técnica 08/2014 (resistência ao fogo dos elementos de construção)", onde a mesma estabelece todas condições a serem atendidas pelos elementos estruturais e de compartimentação da edificação, informa os tempos requeridos de resistência ao fogo (TRRF), para que, em situação de incêndio, seja evitado o colapso estrutural por tempo suficiente para possibilitar a saída segura das pessoas. (SOUSA, 2015).

Atualmente a segurança contra incêndio é considerada nos projetos de instalações elétricas e hidráulicos e nos projetos arquitetônicos. As estruturas de concreto têm boas qualidades com relação a resistência ao fogo, por conta das características térmicas do material, tais como incombustibilidade e baixa condutividade térmica, o concreto não liberar gases tóxicos quando submetido ao calor além de o concreto apresentar maior massa e volume se comparados aos elementos metálicos, ou de madeira. (COSTA, 2002 / SOUSA, 2015). 
Entretanto quando um material entra em contato com temperaturas elevadas suas propriedades são modificadas, com as estruturas de concreto não é diferente, ocasionando assim a redução de sua resistência inicial, podendo levar os componentes da estrutura a ruína.

O estudo tem o intuito de apresentar os cuidados a serem tomados com estruturas de concreto em situação de incêndio, informando a todos os interessados as normas técnicas de seguimento e concepção do projeto que devem seguidas na fase de preparação das estruturas, em seguida devem ser observados os elementos para a análise da estrutura após o incêndio e os materiais que contribuem no retardo do colapso da estrutura.

\section{REVISÃO BIBLIOGRÁFICA}

O concreto armado apresenta boas propriedades compressivas e, devido à unidade entre o aço e o concreto, pode ser considerado um material "homogêneo" à temperatura ambiente. Quando a temperatura for superior a $100^{\circ} \mathrm{C}$, a temperatura do concreto armado aumentará devido às alterações químicas, físicas e mineralógicas da matriz, perdendo, assim, essa característica de um material "homogêneo". (COSTA, 2008).

Para analisar estruturas de alta temperatura, é necessário conhecer as propriedades térmicas do material, principalmente a massa específica, o calor específico, a condutividade térmica e a expansão térmica. Para a análise térmica da seção de elementos estruturais, os três primeiros são indispensáveis. (COSTA, 2008).

Além das propriedades térmicas, também é necessário entender as propriedades mecânicas do material, especialmente a resistência à compressão e tração, módulo de elasticidade e relação tensão-deformação. Normalmente, os modelos matemáticos que representam as propriedades mecânicas dos materiais em função do aumento da temperatura são fornecidos por meio de resultados experimentais ou modelagens numéricas. (COSTA, 2008). 


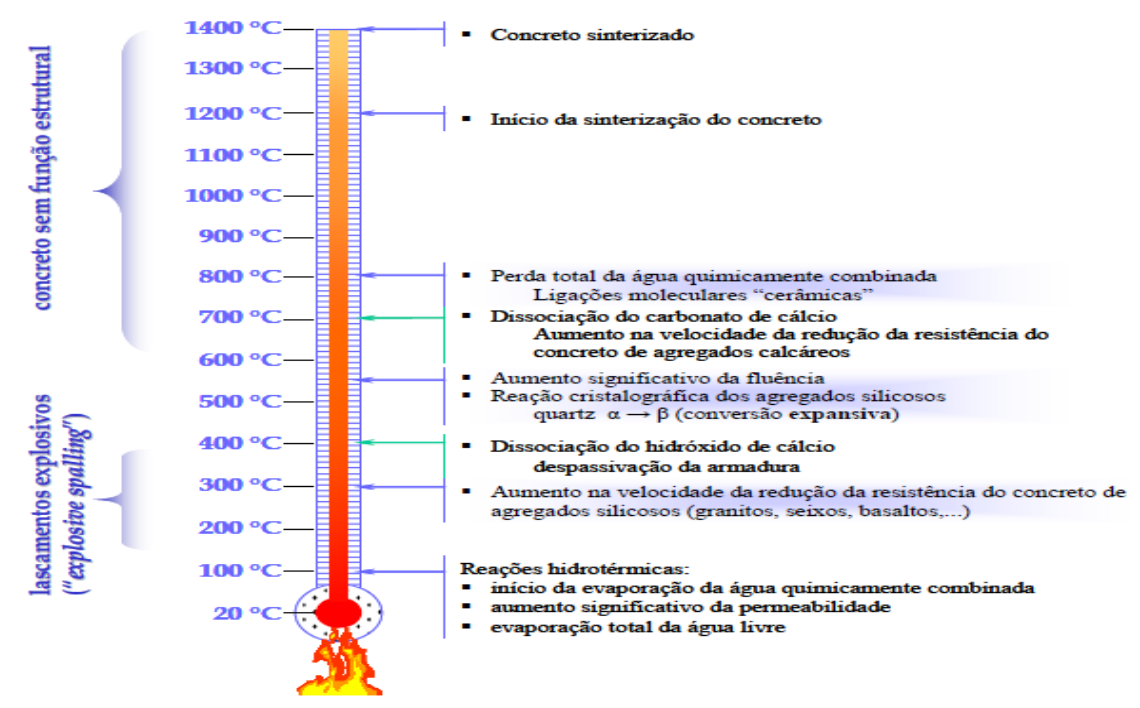

Fonte: (COSTA, 2021).

Independentemente do diâmetro das barras de aço, o concreto que resfria rapidamente na água tem uma queda muito maior na adesão do que quando é resfriado gradualmente no ar. Acima de $100^{\circ} \mathrm{C}$, a diminuição da aderência entre a barra de aço e o concreto é sensível e é função do aumento do tempo de aquecimento e da duração; a partir de $400^{\circ} \mathrm{C}$, a diminuição da aderência da barra de aço é maior que a diminuição da resistência à compressão do concreto. A partir de $600^{\circ} \mathrm{C}$, a adesão é completamente perdida. (COSTA, 2002).

Os incêndios raramente chegam a $1550^{\circ} \mathrm{C}$, o que equivale ao ponto de fusão do aço. Portanto, não há risco de as barras de aço na estrutura de concreto armado derreterem em caso de incêndio. A temperatura máxima atingida é próxima a $1200^{\circ}$ C. O incêndio histórico no Mont Blanc Tunnel, cuja carga de incêndio era altamente inflamável (hidrocarbonetos), durou dois dias e ultrapassou os $1000^{\circ} \mathrm{C}$, mas não há relato de qualquer incêndio no compartimento na literatura técnica, cuja temperatura tenha chegado aos $1550^{\circ} \mathrm{C}$. (COSTA, 2002).

A densidade do aço não varia em função da temperatura elevada e pode ser considerada constante $\rho=7850 \mathrm{~kg} / \mathrm{m}^{3}$. O Eurocode 2 , admite que a resistência do aço se anula completamente aos $1200^{\circ} \mathrm{C}$. À medida que a temperatura se eleva, a taxa de redução do módulo de elasticidade do aço é maior que a observada na resistência. A redução no módulo de elasticidade dos aços laminados é linear até $400^{\circ} \mathrm{C}$ e, a partir daí, decai acentuadamente (COSTA, 2002).

\section{DIRETRIZES PARA CONCEPÇÃO DO PROJETO}

A NBR 15200 de 04/2012 - Projeto de estruturas de concreto em situações de incêndio, determina todos os métodos de projeto de estruturas de concreto em situação de incêndio e o meio de demonstrar seu atendimento, conforme a NBR 14432, que fornecerá todas as solicitações de resistência ao fogo. Para estruturas de concreto projetadas para edifícios temos a NBR 6118. Estruturas de concretos normais, com massa específica seca maior que $2.000 \mathrm{~kg} / \mathrm{m}^{3}$, sem ultrapassar 2.800 $\mathrm{kg} / \mathrm{m}^{3}$, do grupo I de resistência (C20 a C50), de acordo com a classificação da NBR 8953. Para concretos do grupo II de resistência, seguindo a classificação da NBR 
8953, as recomendações do Eurocode 2, Part 1-2, podem ser utilizadas. (PATISEG, 2021 / ABNT NBR 15200:2012).

Para estruturas ou elementos estruturais de concreto pré-moldado ou préfabricados, aplicam-se as condições de certas normas brasileiras. Inexistindo uma norma brasileira própria, aplicam-se as instruções desta norma. Para situações descobertas por esta norma ou de forma simplificada, o pessoal técnico responsável pelo projeto poderá utilizar os procedimentos internacionais aplicáveis ou as normas aceitas pela comunidade técnica e científica, desde que comprove atender ao nível de segurança especificado nesta norma. O projeto de estruturas de concreto em temperatura ambiente $(20 \stackrel{\circ}{\circ})$ deve atender aos requisitos da NBR 6118. (PATISEG, 2021 / ABNT NBR 15200:2012).

O cálculo de estruturas de concreto em situação de incêndio baseia-se na correlação entre o desempenho do material e a estrutura à temperatura ambiente (quando se considera próximo de $20^{\circ} \mathrm{C}$ ) o que ocorre em situação de incêndio. Os objetivos gerais da inspeção de uma estrutura em situação de incêndio, de acordo com a NBR 15200:2012, são limitar o risco à vida humana; o risco da vizinhança e da própria sociedade; o risco da propriedade exposta ao fogo. (PATISEG, 2021 / ABNT NBR 15200:2012).

Se ficar comprovado que a estrutura garante a função de proteção e suporte contra incêndio, é possível concluir que o objetivo estabelecido foi alcançado. As imposições descritas fazem parte das premissas gerais de proteção contra incêndio e incluem, reduzir o risco de incêndio, controlar o fogo em estágios iniciais, limitar a área exposta ao fogo (compartimento corta-fogo), criar rotas de fuga, facilitar a operação de combate ao incêndio e evitar ruína prematura da estrutura, permitindo a fuga dos usuários e as operações de combate ao incêndio. (PATISEG, 2021 / ABNT NBR 15200:2012).

Edifícios maiores, especialmente edifícios que são relativamente altos ou contêm grandes cargas de incêndio, devem atender a requisitos mais rigorosos para atender aos requisitos gerais. Projetos propícios à proteção contra incêndio ou proteção contra incêndio, nos termos desses requisitos gerais, reduzem o risco de incêndio ou sua propagação, principalmente para facilitar as operações de fuga e combate ao usuário, e exigem a resistência ao fogo de sua estrutura, conforme especificado na NBR 14432, este é o método de tempo equivalente detalhado no apêndice A. (PATISEG, 2021 / ABNT NBR 15200:2012).

As duas funções estabelecidas devem ser verificadas no estado limite sob uma combinação anormal de ações, de forma que a plasticidade e as ruínas locais além do colapso local sejam aceitáveis. A NBR 14432 define o comportamento que deve ser considerado na representação de uma situação de incêndio de acordo com as características da estrutura e uso do edifício. Por aceitar plastificação, ruína e até mesmo colapso parcial, a estrutura só pode ser reaproveitada após incêndio seguido de vistoria, verificação da capacidade remanescente, projeto e execução de sua restauração. Esta restauração pressupõe a realização de todas as capacidades finais e de serviço exigidas pelas condições estruturais de uso antes do incêndio ou das novas condições finais de uso. (PATISEG, 2021 / ABNT NBR 15200:2012).

A verificação do plano pode, eventualmente, concluir que se o fogo for pequeno ou a estrutura tiver muita proteção, não há necessidade de reparar a estrutura. As 
propriedades dos materiais variam de acordo com a temperatura $\theta$ que suportam sob a ação do fogo. (PATISEG, 2021 / ABNT NBR 15200:2012).

\subsection{COMO O CONCRETO RESISTE À COMPRESSÃO SOBRE ALTAS TEMPERATURAS}

A resistência à compressão do concreto diminui com o aumento da temperatura, conforme mostra a figura abaixo, podendo ser obtida pela seguinte fórmula: $f_{c, \theta}=k_{c, \theta} . f_{c k}$, onde fck é a resistência à compressão característica do concreto à temperatura ambiente $\left(20^{\circ} \mathrm{C}\right) ; \mathrm{k}_{\mathrm{c}, \theta}$, é o fator de redução da resistência do concreto na temperatura $\theta$, conforme mostrado na figura 1. (ABNT NBR 15200:2012).

Figura 2: Fator de redução da resistência do concreto em função da temperatura.

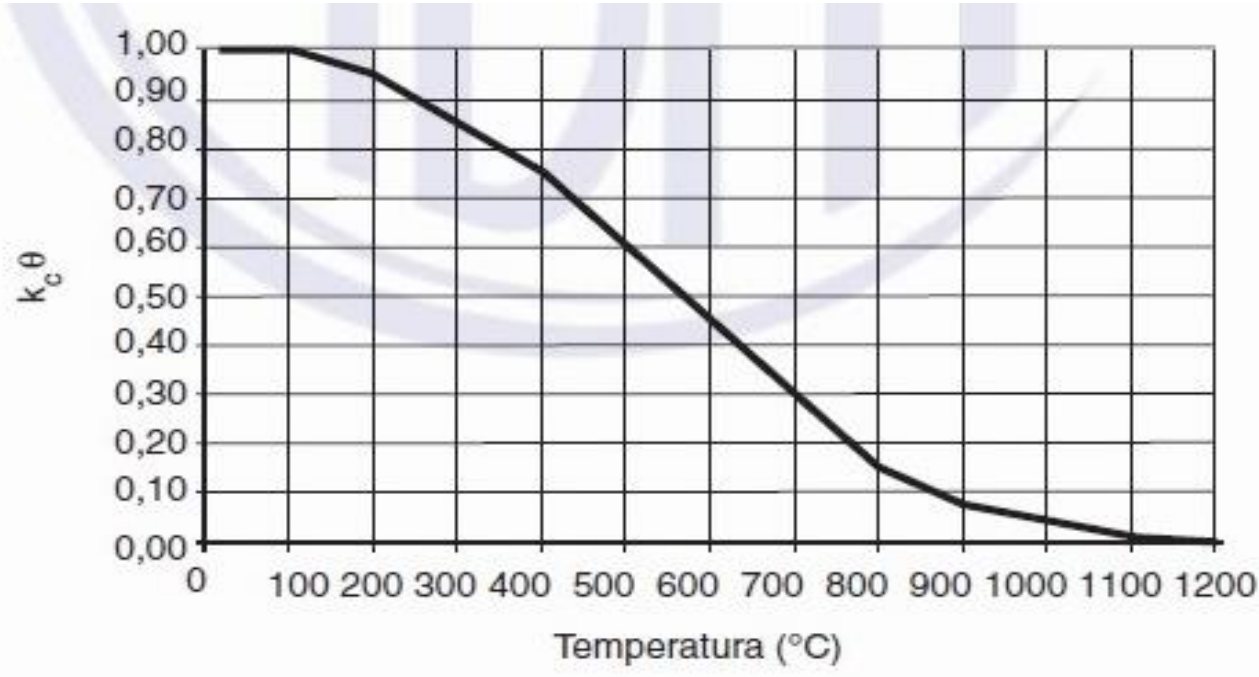

Fonte: (ABNT NBR 15200:2012, 2021)

Em uma análise mais detalhada, cabe destacar que com o aumento da temperatura (representada no eixo das abscissas), o fator de redução do concreto $\mathrm{k}_{\mathrm{c}, \theta}$ (representado no eixo das ordenadas) reduz. Portanto, quanto maior a temperatura sobre o concreto, menor será o coeficiente de redução e a resistência do concreto à compressão ( $\left.f_{c k}\right)$. 
Tabela 1: Valores da relação $\mathrm{k}_{\mathrm{c}, \theta}=\mathrm{f}_{\mathrm{c}, \theta} / \mathrm{f}_{\mathrm{ck}}$ para concretos de massa especifica normal $\left(2.000 \mathrm{~kg} / \mathrm{m}^{3}\right.$ a $\left.2.800 \mathrm{~kg} / \mathrm{m}^{3}\right)$ preparados com agregados predominantemente siliciosos.

\begin{tabular}{|c|c|}
\hline $\begin{array}{c}\text { Temperatura do concreto } \\
{ }^{\circ} \mathrm{C}\end{array}$ & $\boldsymbol{k}_{\mathrm{c}, \boldsymbol{\theta}}=\boldsymbol{f}_{\mathrm{c}, \boldsymbol{\theta}} / \boldsymbol{f}_{\mathrm{ck}}$ \\
\hline 1 & 2 \\
\hline 20 & 1,00 \\
\hline 100 & 1,00 \\
\hline 200 & 0,95 \\
\hline 300 & 0,85 \\
\hline 400 & 0,75 \\
\hline 500 & 0,60 \\
\hline 600 & 0,45 \\
\hline 700 & 0,30 \\
\hline 800 & 0,15 \\
\hline 900 & 0,08 \\
\hline 1000 & 0,04 \\
\hline 1100 & 0,01 \\
\hline 1200 & 0,00 \\
\hline
\end{tabular}

Fonte: (ABNT NBR 15200:2012, 2021)

Para concretos preparados principalmente com agregados siliciosos, esta tabela, reorganizando os dados apresentados na figura 1, fornece a relação entre a resistência à compressão $(\mathrm{fc}, \theta)$ do concreto em diferentes temperaturas e a resistência à compressão característica (fck) do concreto à temperatura ambiente. Para valores de temperatura intermediários, a interpolação linear pode ser realizada.

Para concreto preparado com agregados ou massas específicas diferentes, consulte o Eurocode 2 Parte 1-2. (ABNT NBR 15200:2012).

\subsection{RESISTÊNCIA DO AÇO AO ESCOAMENTO E MÓDULO DE ELASTICIDADE EM UMA ARMADURA PASSIVA A ALTAS TEMPERATURAS}

A resistência do aço ao escoamento para a armadura passiva diminui com o aumento da temperatura, conforme mostrado na figura 2 , adotando a equação $f_{y, \theta}=$ $\mathrm{k}_{\mathrm{s}, \theta} . \mathrm{f}_{\mathrm{y} k}$, onde $\mathrm{f}_{\mathrm{yk}}$ é a resistência do aço da armadura passiva à temperatura ambiente $\left(20{ }^{\circ} \mathrm{C}\right)$, e $\mathrm{k}_{\mathrm{s}, \theta}$ é o fator de redução da resistência do aço na temperatura $\theta$, como demonstra a tabela 2. (ABNT NBR 15200:2012).

$\mathrm{Na}$ figura abaixo temos a relação entre a resistência do aço da armadura passiva e o aumento da temperatura. Onde a curva cheia mostra $0 \mathrm{k}_{\mathrm{s}, \theta}$ aplicável quando $\varepsilon_{y i} \geq 2 \%$, normalmente usados em armaduras tracionadas de vigas, lajes ou tirantes. $\mathrm{E}$ a curva tracejada mostra o $\mathrm{k}_{\mathrm{s}, \theta}$ aplicável quando $\varepsilon_{y i}<2 \%$, normalmente usados em armaduras comprimidas de pilares, vigas ou lajes. (ABNT NBR 15200:2012). 
Figura 3: Fator de redução da resistência do aço de armadura passiva em função da temperatura.

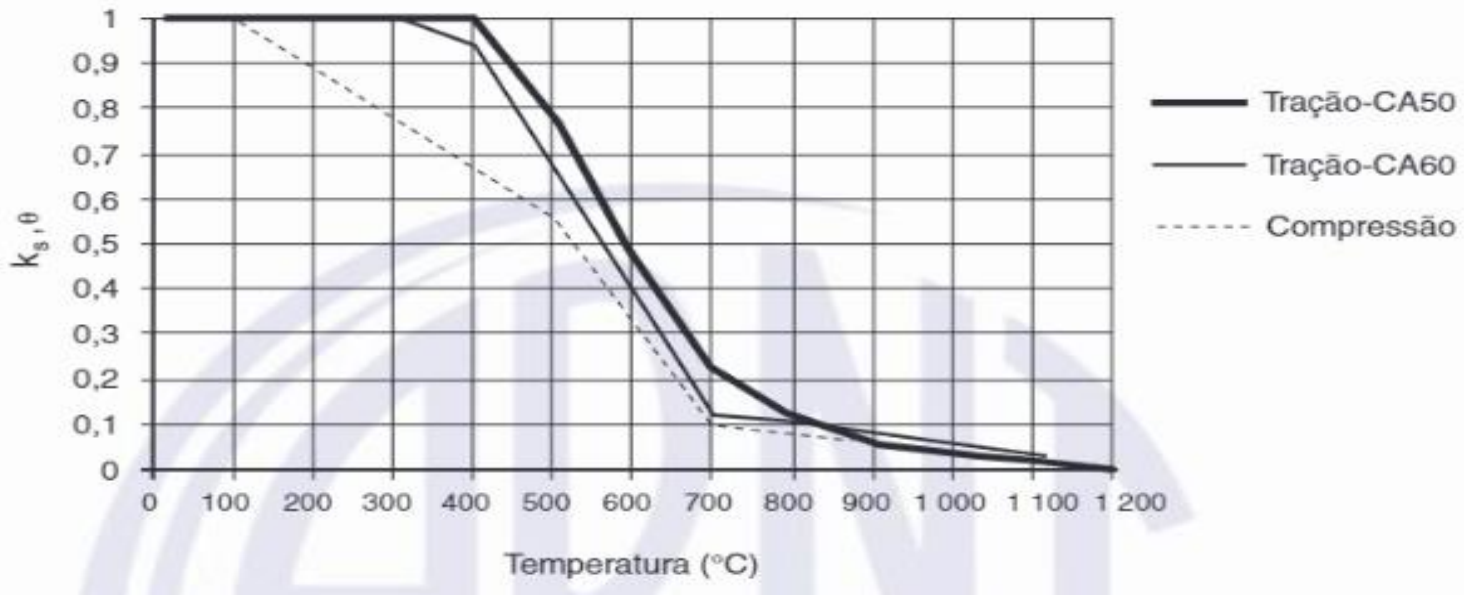

Fonte: (ABNT NBR 15200:2012, 2021)

A seguir, demonstrado na figura 3, tem-se a diminuição do módulo de elasticidade do aço em uma armadura passiva à medida que a temperatura aumenta. Representado pela equação $\mathrm{E}_{\mathrm{s}, \theta}=\mathrm{k}_{\mathrm{Es}, \theta} . \mathrm{E}_{\mathrm{s}}$, onde $\mathrm{E}_{\mathrm{s}}$ é o módulo de elasticidade do aço de uma armadura passiva à temperatura ambiente, e $\mathrm{k}_{\mathrm{Es}, \theta} \theta$ é o fator de redução do módulo de elasticidade do aço na temperatura $\theta$, que será demonstrado posteriormente na tabela 2. (ABNT NBR 15200:2012).

Figura 4: Fator de redução do módulo de elasticidade do aço de armadura passiva em função da temperatura.

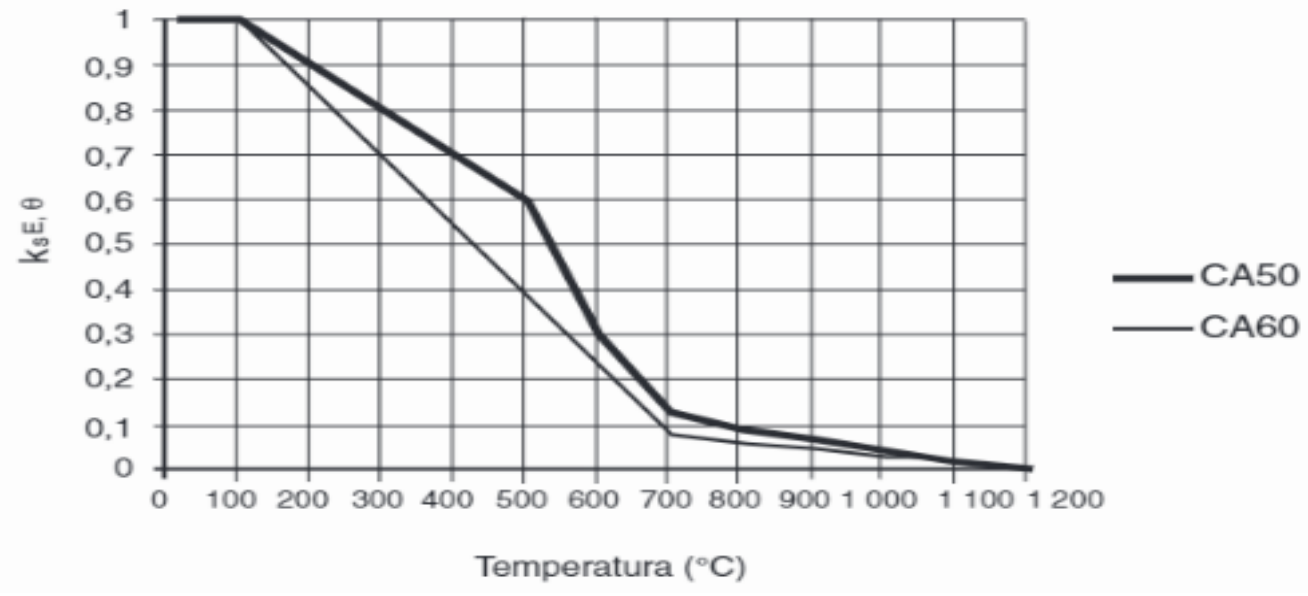

Fonte: ABNT NBR 15200:2012

A tabela 2 apresenta, em conjunto, o fator de redução da resistência do aço $\left(\mathrm{k}_{\mathrm{s}, \theta}\right) \mathrm{e}$ o fator de redução do módulo de elasticidade $\left(\mathrm{k}_{\mathrm{sE}, \theta}\right)$ de uma armadura passiva em função da temperatura. Para valores intermediários de temperatura pode-se adotar uma interpolação linear. 
Tabela 2: Valores da relação $\mathrm{k}_{\mathrm{s}, \theta}=\mathrm{f}_{\mathrm{y}, \theta} / \mathrm{f}_{\mathrm{yk}}$ e $\mathrm{k}_{\mathrm{sE}, \theta}=\mathrm{E}_{\mathrm{s}, \theta} / \mathrm{E}_{\mathrm{s}}$

\begin{tabular}{|c|c|c|c|c|c|}
\hline \multirow{3}{*}{$\begin{array}{c}\text { Temperatura do } \\
\text { aço } \\
{ }^{\circ} \mathrm{C}\end{array}$} & \multicolumn{3}{|c|}{$K_{\mathrm{s}, \theta}=f_{\mathrm{yk}, \theta} / f_{\mathrm{yk}}$} & \multicolumn{2}{|c|}{$k_{\mathrm{Es}, \theta}=E_{\mathbf{s}, \theta} / E_{\mathbf{s}}$} \\
\hline & \multicolumn{2}{|c|}{ Tração } & \multirow{2}{*}{$\begin{array}{c}\text { Compressão } \\
\text { CA-50 ou CA-60 }\end{array}$} & \multirow[b]{2}{*}{ CA-50 } & \multirow[b]{2}{*}{ CA- 60} \\
\hline & CA- 50 & CA- 60 & & & \\
\hline 1 & 2 & 3 & 4 & 5 & 6 \\
\hline 20 & 1,00 & 1,00 & 1,00 & 1,00 & 1,00 \\
\hline 100 & 1,00 & 1,00 & 1,00 & 1,00 & 1,00 \\
\hline 200 & 1,00 & 1,00 & 0,89 & 0,90 & 0,87 \\
\hline 300 & 1,00 & 1,00 & 0,78 & 0,80 & 0,72 \\
\hline 400 & 1,00 & 0,94 & 0,67 & 0,70 & 0,56 \\
\hline 500 & 0,78 & 0,67 & 0,56 & 0,60 & 0,40 \\
\hline 600 & 0,47 & 0,40 & 0,33 & 0,31 & 0,24 \\
\hline 700 & 0,23 & 0,12 & 0,10 & 0,13 & 0,08 \\
\hline 800 & 0,11 & 0,11 & 0,08 & 0,09 & 0,06 \\
\hline 900 & 0,06 & 0,08 & 0,06 & 0,07 & 0,05 \\
\hline 1000 & 0,04 & 0,05 & 0,04 & 0,04 & 0,03 \\
\hline 1100 & 0,02 & 0,03 & 0,02 & 0,02 & 0,02 \\
\hline 1200 & 0,00 & 0,00 & 0,00 & 0,00 & 0,00 \\
\hline
\end{tabular}

Fonte: (ABNT NBR 15200:2012, 2021)

Analisando o gráfico, nota-se que o o aço CA-50 se sobressai ao CA-60 em relação ao trabalho em altas temperatura. O fator de redução da resistência do CA-50 é maior do que o do CA-60 até $800{ }^{\circ} \mathrm{C}$, e o seu fator de redução do módulo de elasticidade é superior em todas as temperaturas, igualando-se ao CA-60 apenas em $1100 \stackrel{\circ}{\mathrm{C}}$ e $1200 \stackrel{\circ}{\mathrm{C}}$.

\subsection{RESISTÊNCIA DO AÇO AO ESCOAMENTO E MÓDULO DE ELASTICIDADE EM UMA ARMADURA ATIVA A ALTAS TEMPERATURAS}

A resistência do aço ao escoamento para a armadura ativa também diminui com o aumento da temperatura, adotando a equação $f_{p y k, \theta}=k_{p, \theta} . f_{p y k}$, onde $f_{p y k}$ é a resistência do aço da armadura ativa à temperatura ambiente $\left(20^{\circ} \mathrm{C}\right)$, e $\mathrm{k}_{\mathrm{p}, \theta}$ é o fator de redução da resistência do aço na temperatura $\theta$. (ABNT NBR 15200:2012).

O módulo de elasticidade do aço para a armadura ativa também irá reduzir com o aumento da temperatura, sendo expressa pela equação $E_{p, \theta}=k_{E p, \theta} . E_{p}$, onde temos que $E_{p}$ é o módulo de elasticidade do aço da armadura ativa à temperatura ambiente $\left(20{ }^{\circ} \mathrm{C}\right)$, e kEp,e é o fator de redução do módulo de elasticidade do aço da armadura ativa na temperatura $\theta$. (ABNT NBR 15200:2012). 
Tabela 3: Valores da relação $\mathrm{f}_{\mathrm{pyk}, \theta} /\left(0,9 . \mathrm{f}_{\mathrm{pyk}}\right)$ e $\mathrm{E}_{\mathrm{p}, \theta} / \mathrm{E}_{\mathrm{p}}$ para fios e cordoalhas da armadura ativa

\begin{tabular}{|c|c|c|}
\hline \multirow{2}{*}{$\begin{array}{c}\text { Temperatura do aço } \\
{ }^{C} \mathrm{C}\end{array}$} & $\boldsymbol{f}_{\mathrm{pyk}, \Theta} /\left(\mathbf{0 , 9} \boldsymbol{f}_{\mathrm{pyk}}\right)$ & $\boldsymbol{E}_{\mathrm{p}, \Theta} / \boldsymbol{E}_{\mathrm{p}}$ \\
\cline { 2 - 3 } & Fios e cordoalhas & Fios e cordoalhas \\
\hline 20 & 1,00 & 1,00 \\
\hline 100 & 0,99 & 0,98 \\
\hline 200 & 0,87 & 0,95 \\
\hline 300 & 0,72 & 0,88 \\
\hline 400 & 0,46 & 0,81 \\
\hline 500 & 0,22 & 0,54 \\
\hline 600 & 0,10 & 0,41 \\
\hline 700 & 0,08 & 0,10 \\
\hline 800 & 0,05 & 0,07 \\
\hline 900 & 0,03 & 0,03 \\
\hline 1000 & 0,00 & 0,00 \\
\hline 1100 & 0,00 & 0,00 \\
\hline 1200 & 0,00 & 0,00 \\
\hline
\end{tabular}

Fonte: ABNT NBR 15200:2012

A tabela acima apresenta a relação entre a resistência ao escoamento do aço da armadura ativa em diferentes temperaturas $\left(f_{p y k}, \theta\right)$ e $90 \%$ da resistência do aço ao escoamento à temperatura ambiente $\left(f_{\text {pyk }}\right)$.

A mesma informa também a relação entre o módulo de elasticidade do aço da armadura ativa submetido a diferentes temperaturas $\left(E_{p, \theta}\right)$ e o módulo de elasticidade do aço à temperatura ambiente $\left(E_{p}\right)$. Para valores intermediários de temperatura, pode-se adotar o método de interpolação linear, e para armadura ativa de barras devese consultar o Eurocode 2, parte 1-2. (ABNT NBR 15200:2012).

Reorganizando os dados da tabela temos os seguintes gráficos:

Figura 5: Fator de redução da resistência do aço de armadura ativa por fios ou cordoalhas em função da temperatura.

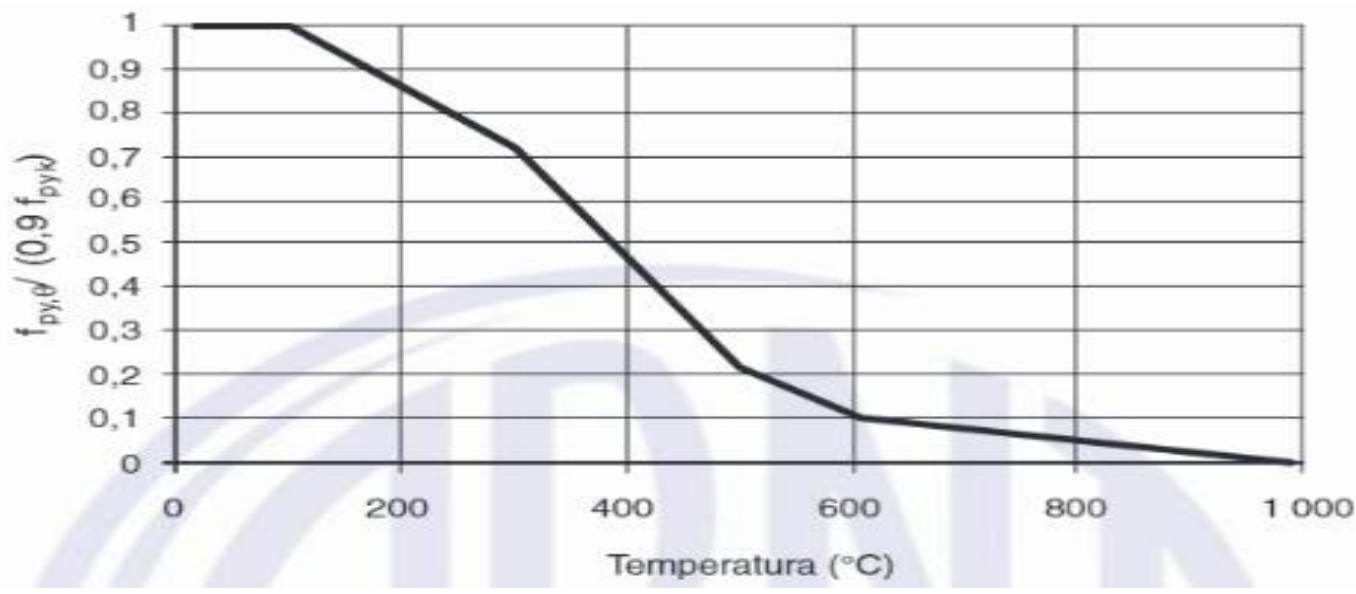

Fonte: (ABNT NBR 15200:2012, 2021) 
Figura 6: Fator de redução do módulo de elasticidade do aço de armadura ativa em função da temperatura.

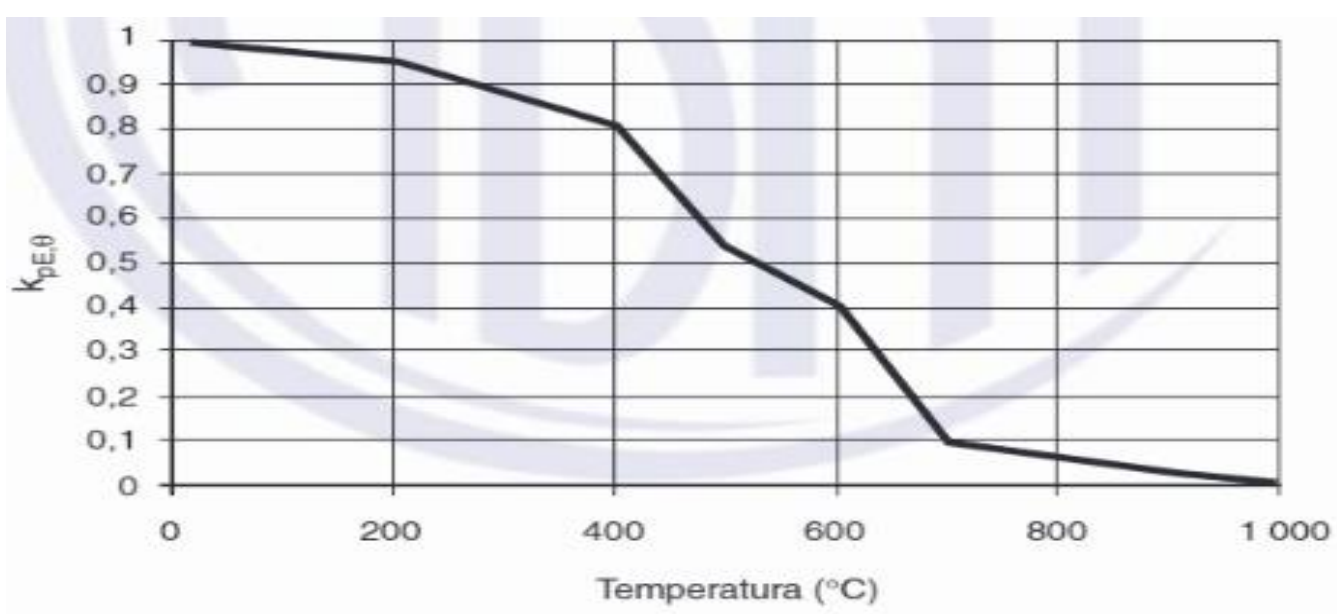

Fonte: (ABNT NBR 15200:2012, 2021)

Deve-se considerar a aplicação de todos os fatores de redução para a concepção do projeto, além disso o seguimento da norma ABNT NBR 15200:2012 é de suma importância, já que a mesma estabelece todas as diretrizes para a realização do projeto.

\section{ELEMENTOS NECESSÁRIOS PARA A ANÁLISE DA ESTRUTURA APÓS O INCÊNDIO}

Para a reabilitação da estrutura deve-se realizar uma inspeção geral, com o intuito de analisar a eficiência de todos os componentes estruturais. Esse estudo tem o intuito de reconhecer e descobrir quais as anomalias e condições presentes, analisando a perda de resistência do concreto e das armaduras de lajes, vigas e pilares, variações do módulo de elasticidade do concreto, corrosão de armadura, trincas e desplacamentos. A seguir temos alguns dos procedimentos para servir como guia, para a realização dos ensaios e testes. (POY, 2020).

\subsection{ANÁLISE DA COLORAÇÃO DO CONCRETO}

Segundo CÁNOVAS (1988) podemos determinar a temperatura que o concreto foi exposto através da análise da coloração do mesmo (que tem característica permanente). A figura abaixo mostra a correlação entre a temperatura atingida em um incêndio com a redução da resistência à compressão do concreto, e ainda informa a mudança de coloração em diferentes graus de temperatura. (POY, 2020). 
Figura 7: Variação da resistência à compressão e coloração do concreto, em função da temperatura atingida.

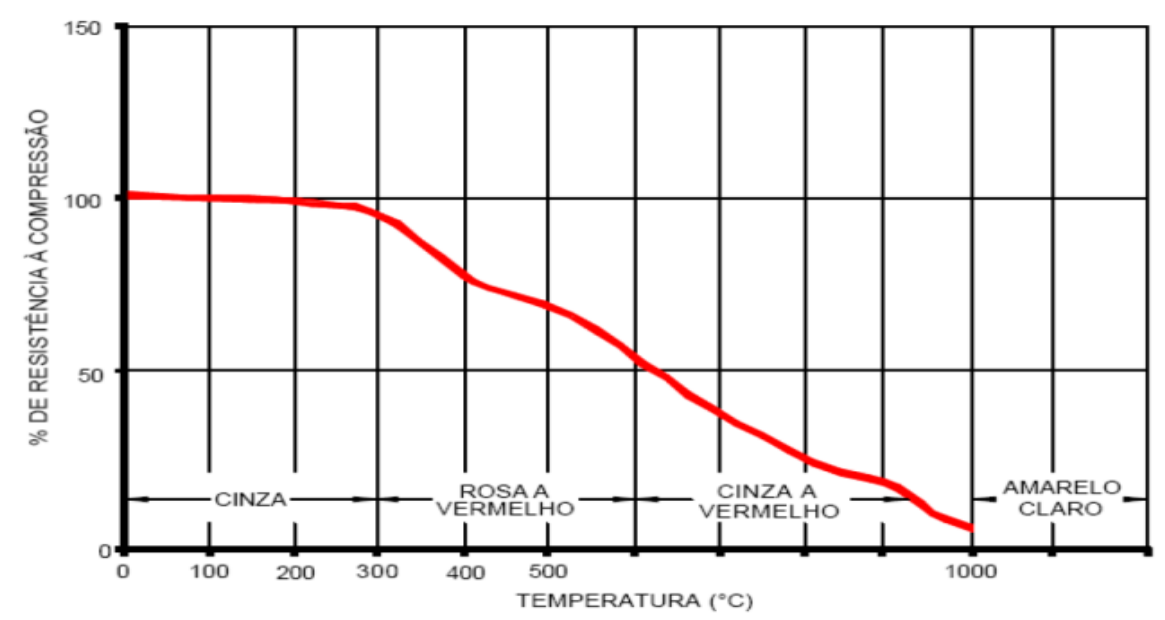

Fonte: (CÁNOVAS (1988), 2021)

Desta maneira, analisando a coloração do concreto, através de corpos de provas, pode-se determinar a temperatura atingida no local e consequentemente 0 fator de redução do concreto.

\subsection{VERIFICAÇÃO DAS DEFORMAÇÕES EM FUNÇÃO DA TEMPERATURA}

Nesta etapa iremos analisar o fator de redução do módulo de elasticidade dos materiais da estrutura em função da temperatura, mais especificamente serão analisados os componetes estruturais cono o aço e o concreto.

Silva (2012) apresenta um gáfico que correlaciona a temperatura atingida com a redução do módulo de elasticidade de alguns materiais, contemplando o aço e o concreto. (POY, 2020).

Figura 8: Variação do módulo de elasticidade de alguns materiais em função da temperatura.

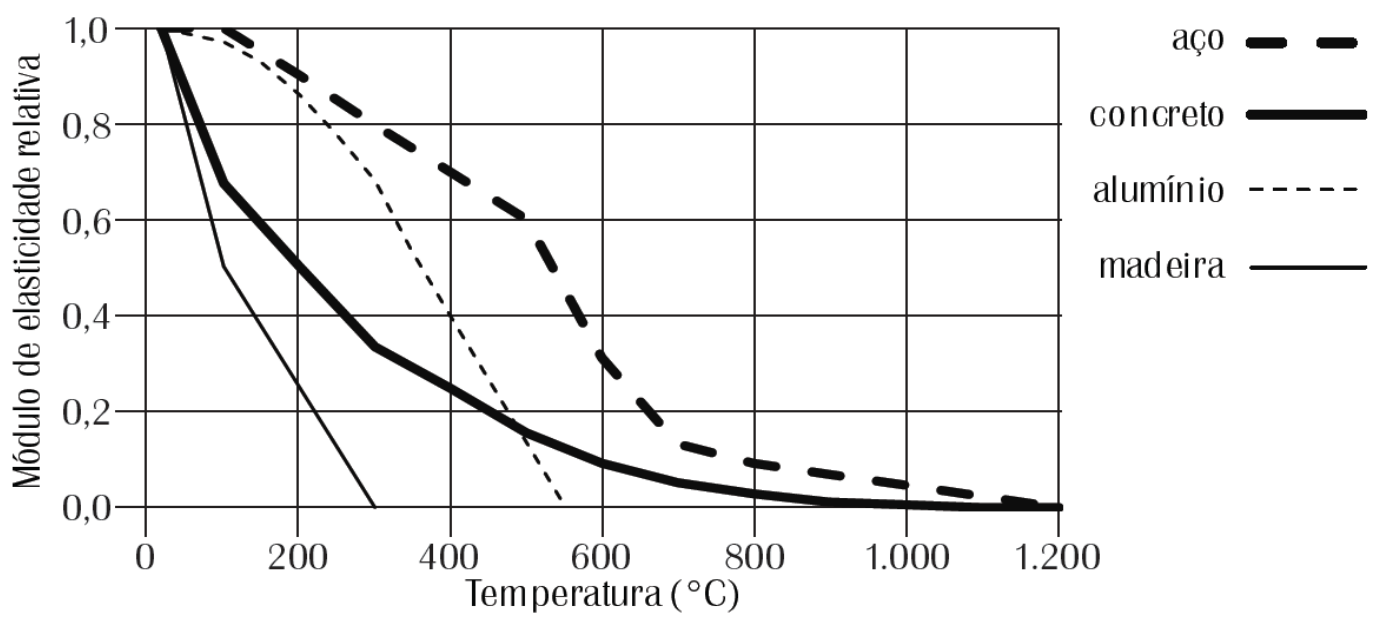

Fonte: (SILVA (2012), 2021) 
Com a medição das deformações nos componentes estruturais pode-se análisar se as medidas obtidas são inferiores ou superiores aos limites estabelecidos pelas normas técnicas aplicáveis a construção. Caso as medidas sejam inferiores sugere-se que não houve diminuição significativo dos módulos de elasticidades do aço e do concreto, não comprometendo a estrutura. Caso as medidas sejam superiores houve uma diminuição significativa dos módulos de elasticidade do componentes estruturais, comprometendo assim a estrutura, deve-se estudar a viabilidade de reforços estruturais, ou até mesmo declarar a ruína da estrutura.

\subsection{VERIFICAÇÃO DA EXISTÊNCIA DE FISSURAÇÃO}

Nesta etapa é realizada a verificação da existência e o grau de fissuração das estruturas. Essas fissuras ocorrem por causa das movimentações térmicas, em decorrência da alta temperatura durante o incêndio. Quanto maior for a fissura, significa que maior foi a movimentação térmica e, consequentemente, indica que a estrutura ficou exposta a altas temperaturas, ocasionando uma agressão maior na estrutura e em seus componentes por conta do incêndio, gerando um coeficiente de redução menor nos componentes da estrutura, reduzindo a resistência da estrutura. (POY, 2020).

\subsection{ANÁLISE DO PH DO CONCRETO}

As análises do $\mathrm{pH}$ do concreto podem ser realizadas nos locais onde foram retirados os corpos de prova. Contudo essa análise tem o intuito de indicar se houve redução da alcalinidade do concreto, ao realizar a combinação da carbonatação com a calcinação. (POY, 2020).

\subsection{DETERMINAÇÃO DA RESISTÊNCIA DO CONCRETO À COMPRESSÃO}

Para determinar a resistência do concreto deve-se extrair os corpos de provas em componentes estruturais, como lajes, pilares e vigas, levando-os à analise em laboratório. Com os resultados obtidos, podemos analisar se a resistência dos mesmos encaixam-se na resistência de projeto da estrutura. Se a resistência não estiver de acordo com a resistência de projeto, deve-se realizar um cálculo estrutural para a resistência obtida em laboratório. (POY, 2020).

\subsection{ESTIMATIVA DA RESISTÊNCIA DO CONCRETO, COM O USO DO ESCLERÔMETRO}

A utilização do esclerômetro nesta fase é de suma importância, tendo em vista que o equipamento irá medir a dureza superficial do concreto, e com isso estimar a resistência do concreto, os ensaios por esclerometria deve atender os requisitos da ABTN NBR 7584:2012 Concreto endurecido - Avaliação da dureza superficial pelo esclerômetro de reflexão. (POY, 2020). 
Figura 9: Esclerômetro.

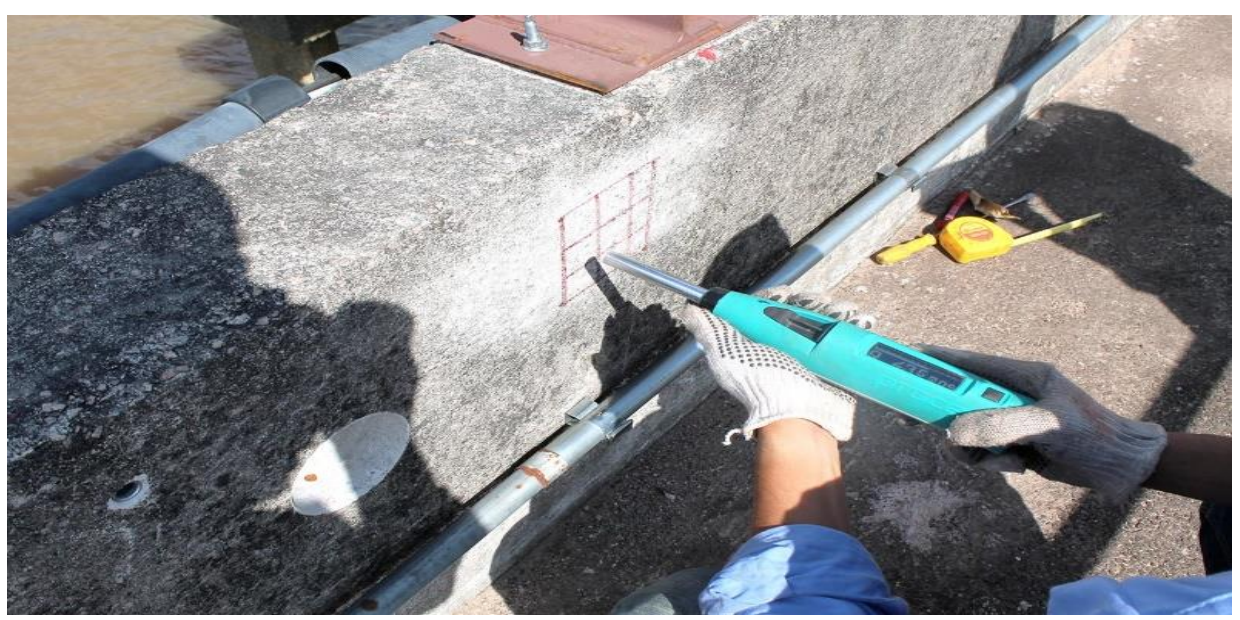

Fonte: (Dynamistechne.com,, 2021)

\subsection{DETERMINAÇÃO DA RESISTÊNCIA DO AÇO À TRAÇÃO}

Conhecendo o fato que a alta temperatura prejudica significativamente 0 comportamento do aço estrutural, para a determinação da resistência do aço estrutural utilizaremos os dados apresentados na figura 2, figura 3 e tabela 3.

Um adendo importante é que, embora os aços tipo "B" (trabalhados a frio), mesmo não sendo mais produzidos usualmente, encontram-se presentes em muitas estruturas de edificações antigas. Sendo assim um grande problema, pois segundo Costa, Figueiredo e Silva (2002), a partir de $600{ }^{\circ} \mathrm{C}$ estes aços sofrem perdas de resistência mecânica permanente e da ordem de 50\%, comprometendo assim a capacidade da estrutura. (POY, 2020).

\subsection{ANÁLISE DE CORROSÃO NAS ARMADURAS}

Mesmo com as armaduras da estrutura não estando expostas visualmente, deve-se verificar, pois com o baixo $\mathrm{pH}$ do concreto propicia a constatação de processos corrosivos importantes e generalizados, comprometendo a vida útil da estrutura. (POY, 2020).

\section{MATERIAIS QUE CONTRIBUEM NO RETARDO DO COLAPSO DA ESTRUTURA}

Sabemos que o fogo pode ocasionar estragos incalculáveis a uma estrutura, visando evitar o colapso ou a ruína dessas estruturas, os projetistas podem prever a utilização de sistema contra incêndio em suas obras. Nesta lista de equipamento contemplam os extintores, hidrantes, detectores de incêndio, sinalização de emergência, bombeiros, sprinklers e os revestimentos contrafogo em certos componentes estruturais. (ENGENHARIA 360, 2021).

Estes revestimentos estruturais contrafogo fazem parte de uma nova geração de produtos para a proteção passiva contrafogo presente nas construções atuais. São 
uma ótima alternativa para a segurança do patrimônio construtivo, com um desenvolvimento sustentável do planeta. (ENGENHARIA 360, 2021).

Atualmente existem duas maneiras de proteger as construções do fogo. O primeiro é modo passivo, que é composto por tudo aquilo previsto na etapa de projeto de arquitetura e engenharia. O segundo é o modo ativo, tendo a função complementar, sendo utilizado apenas quando as chamas se espalham pela edificação. É importante ressaltar, que apenas um especialista em engenharia de incêndios (como um engenheiro civil) pode dar as diretrizes e dizer quais a melhores soluções para cada projeto. (ENGENHARIA 360, 2021).

Temos conhecimento do modo ativo de proteção das construções, ele é constituído por elementos como os extintores, hidrantes, detectores de incêndio, sinalização de emergência, bombeiros, sprinklers, entre outros. Já o modo de proteção passivo contempla as paredes corta fogo, a tinta intumescente, a argamassa projetada contrafogo e o envelopamento por meio de chapas de silicato de cálcio. (PROMAT, 2021 / ENGENHARIA 360, 2021).

\subsection{PAREDES CORTA FOGO}

O principal objetivo da parede corta fogo é evitar que o fogo se espalhe para outros ambientes, proteger as pessoas e o próprio edifício de novos danos causados pelo incêndio. Portanto, a escolha de uma empresa especializada em proteção passiva contra incêndio é muito importante para o desenvolvimento do projeto. (GUARUTHERM, 2021).

A estrutura da parede corta fogo é feita de materiais específicos e pode suportar o calor por um determinado período. Isso significa que é um elemento complementar para evitar a propagação do fogo, mas outras medidas devem ser tomadas para cancelar a propagação. Atualmente encontra-se paredes corta fogo moldadas in loco, pré-moldadas e em drywall. (GUARUTHERM, 2021).

A construção da parede corta fogo deve obedecer às normas NBR 6479 e NBR 14432 e às orientações técnicas do corpo de bombeiros (IT 08 e 09). Todos os padrões são para estruturas que podem resistir ao colapso estrutural, permitindo que medidas adicionais sejam tomadas em um prazo de até 120 minutos. (GUARUTHERM, 2021).

O tipo de material usado para a estrutura da parede corta fogo pode ser gesso especial, lã mineral ou adição de fibras de polipropileno na mistura do concreto. A escolha entre os dois é definida no desenvolvimento do projeto, levando em consideração o custo e o tempo de execução. Independentemente da escolha, a estrutura da parede corta fogo usará materiais especiais que podem suportar o fogo e retardar sua propagação. (GUARUTHERM, 2021 / CKC, 2021).

Deve-se considerar que as estruturas metálicas perdem resistência quando expostas a altas temperaturas, portanto, cada elemento selecionado para a construção da parede corta fogo deve suprir essa deficiência. Além da estrutura das paredes, quaisquer outros elementos que façam parte da construção devem ser resistentes ao fogo, como portas, janelas e vidros. (GUARUTHERM, 2021). 
Figura 10: Parede corta fogo pré-moldada.

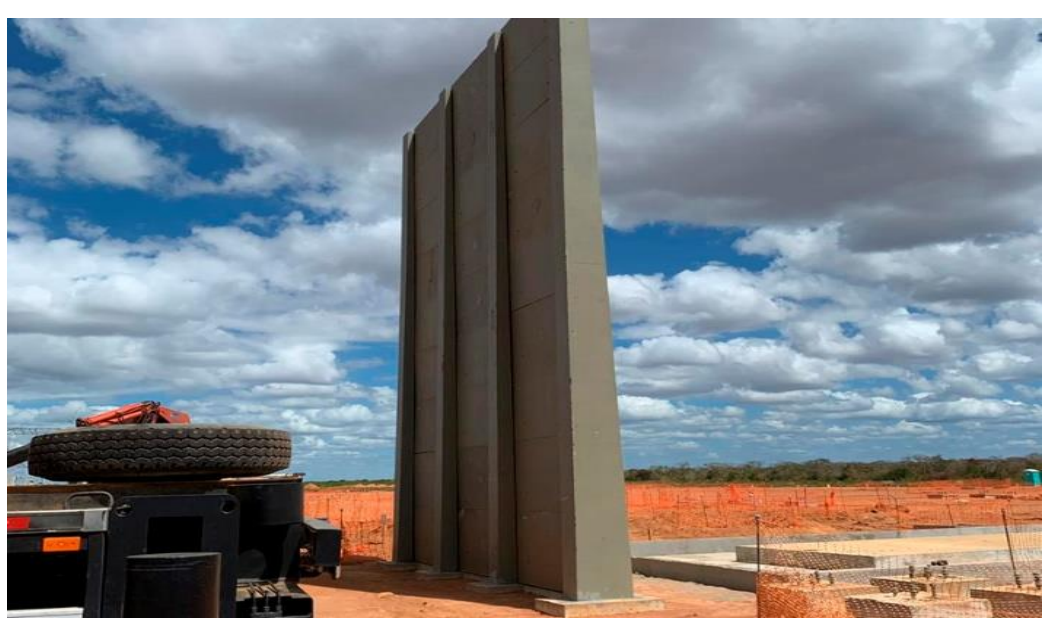

Fonte: (estrelapremoldados.com.br, 2021)

\subsection{TINTA INTUMESCENTE}

Atualmente as tintas intumescentes vem ganhando um grande espaço no cenário construtivo, no quesito barreira contrafogo, provando ser um material econômico, prático e seguro, além de sua aplicação não exigir nenhum processo complexo, já que a mesma se assemelha com uma pintura convencional, com apenas uma diferença, quando esse produto entrar em contato com temperaturas superiores à $200^{\circ} \mathrm{C}$, se expande, formando uma camada carbonizada de proteção, protegendo assim a estrutura. (CKC, 2021).

Estas tintas não só impedem que o fogo seja confinado àquele ambiente, mas também assegura que as temperaturas não se elevem a mais de $180^{\circ} \mathrm{C}$ nos ambientes adjacentes. As mesmas atendem as especificações da norma ASTM E119, suportando um tempo de exposição sem perder sua característica de até 120 minutos. (CKC, 2021).

A vantagem de usar esse material, é que essas tintas são a base de água, que possuem baixo Composto Orgânico Voláteis (VOC), não atacando organismos de crianças, idosos e dos próprios aplicadores. Essas tintas não possuem um odor muito forte, contém baixa toxicidade e não deixam manchas e nem resíduos permanentes nos materiais tratados. (CKC, 2021).

A imagem abaixo representa a camada carbonizada formada pela tinta intumescente. Pode-se notar a carbonatação gradual, garantindo que as chamas não atinjam a estrutura que está sendo protegida tão facilmente. Na imagem foi utilizada uma chapa metálica, porém o mesmo processo de carbonatação ocorre em estrutura de alvenaria, concreto, pré-fabricados, entre outros. 
Figura 11: Sequência acompanha a formação da espuma que protege o substrato.

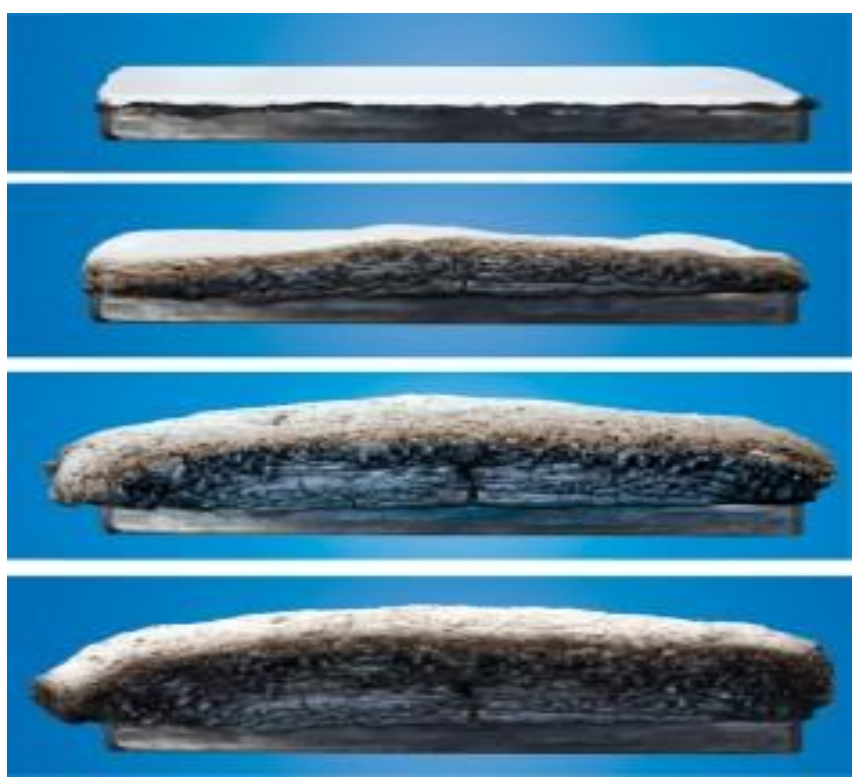

Fonte: (quimica.com.br, 2021)

\subsection{ARGAMASSA PROJETADA CONTRA FOGO}

As argamassas projetadas são usualmente utilizadas para a proteção passiva contra fogo em estruturas metálicas, também podendo ser aplicadas em estruturas de concreto. É indicada sua utilização em qualquer tipo de edificação de grande, médio e pequeno porte, o ideal é que as estruturas de aplicação estejam ocultas por forros falso ou acabamentos arquitetônicos, com o intuito da edificação ficar com uma estética aceitável, já que a argamassa projetada acaba tendo um acabamento rústico. (PFC, 2021 / MERCORTECRESA, 2021).

Utilizadas também em estruturas aparentes, a argamassa projetada tem que estar localizada em áreas livres de intemperismo e solicitações mecânicas. Por seu aspecto ser rústico, a área tem que ser compatível arquitetonicamente sendo ideal para vigas de estacionamentos ou fabricas. (PFC, 2021).

Atualmente este método de proteção encontra-se entre os mais baratos que existem para a proteção passiva contra fogo. $O$ custo para a aquisição dessa proteção varia conforme o Tempo de Resistência Requerido ao Fogo (TRRF), a massa dos perfis de aplicação e as quantidades a serem aplicadas. O TRRF é dado pela espessura da camada de cobrimento, podendo chegar até 240 minutos. (PFC, 2021 / PORTAL INCÊNDIO, 2021).

As vantagens desse método de proteção são:

- Proteção passiva contra fogo em estruturas metálicas, evitando colapso estrutural em conformidade com IT-08 do Corpo de Bombeiros;

- Instalação rápida e segura, fazendo com que o cliente não perca tempo durante a sua aplicação; 
- Homologação para até três horas de fogo;

- Excelente custo benefício;

- Fornecimento de laudo técnico. (GUARUTHERM, 2021).

Figura 12: Argamassa Projetada Contra Fogo.

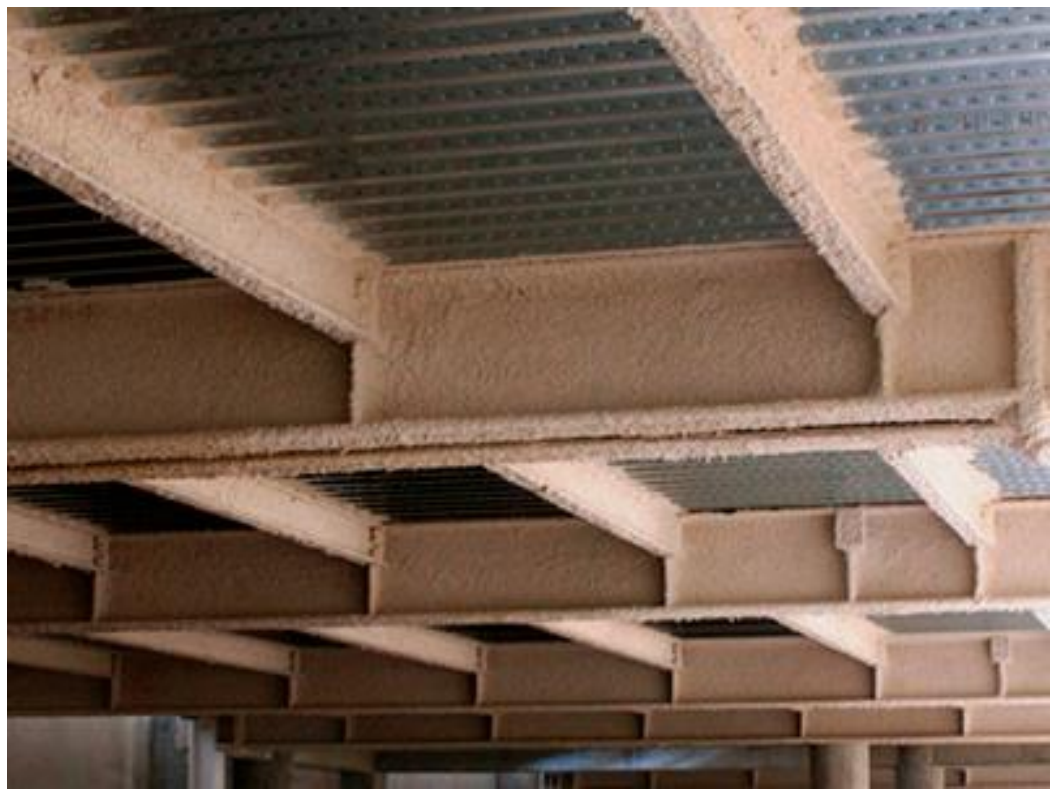

Fonte: (isolamentoacusticosp.com.br, 2021)

\subsection{ENVELOPAMENTO POR MEIO DE CHAPAS DE SILICATO DE CÁLCIO}

São materiais de gesso normalmente utilizados para estruturas metálicas, podendo ser utilizados em estruturas de concreto. São cortados na forma de placas de $15 \mathrm{~mm}$ nas dimensões exigidas e envolvidos na estrutura de acordo com as normas adequadas. Em alguns casos, é necessário selar as juntas entre os painéis com materiais à prova de fogo para fornecer proteção eficaz em caso de incêndio. (PORTAL INCÊNDIO, 2021).

Por ocuparem espaço em áreas úteis e serem mais frágeis, não é recomendável colocá-los em garagens ou áreas expostas a choques mecânicos. Devido ao processo e instalação da placa, o tempo de instalação geralmente é mais longo. Possui o custo de aquisição mais alto dos sistemas de proteção citados acima, se tornando não muito usual atualmente. (PORTAL INCÊNDIO, 2021). 
Figura 13: Argamassa Projetada Contra Fogo.

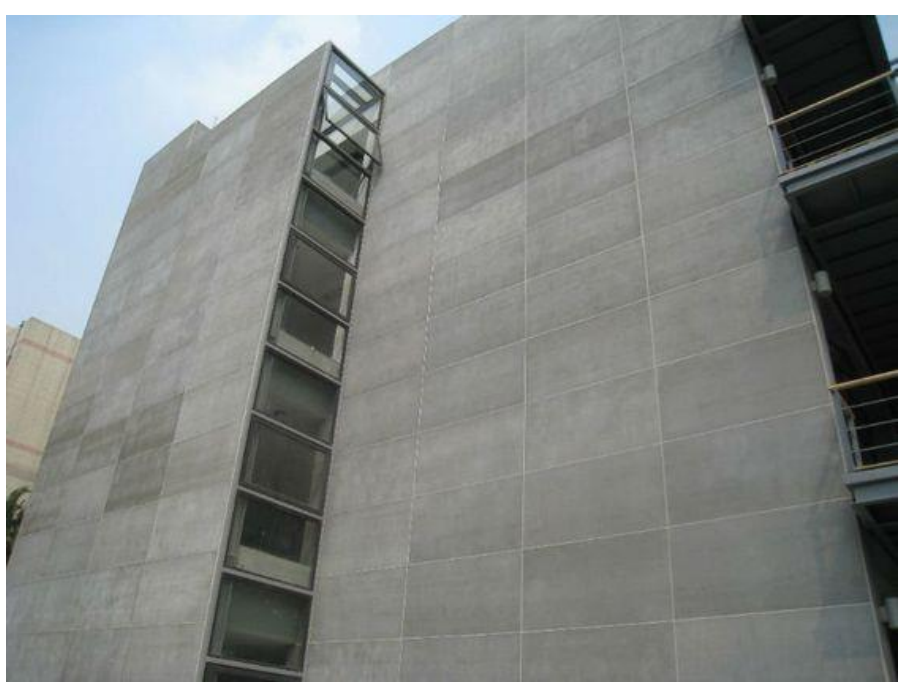

Fonte: aexlusiva.com

\section{CONCLUSÃO}

Os incêndios são grandes inimigos da humanidade desde os primórdios dos tempos, causando grandes impactos ambientais, sociais e econômicos. Desde sempre os ser humano vem criando e aprimorando os sistemas de combate a incêndio. O presente estudo ressalta as normativas que devem ser seguidas antes da concepção de um projeto de estrutura de concreto, mostrando os coeficientes de redução dos materiais presentes na estrutura. Com as mesmas trabalhando na compressão, e tração, além de informar como o módulo de elasticidade desses materiais se comporta em diversas situações de temperatura. Lembrando que o seguimento dessas normas é de suma importância para a realização do projeto.

O estudo também informa as diretrizes para uma análise de uma estrutura após o ocorrido do incêndio, como a análise da coloração do concreto, a verificação das deformações em função da temperatura, a verificação da existência de fissuração, a análise do pH do concreto, a determinação da resistência do concreto à compressão, a estimativa da resistência do concreto com o uso do esclerômetro, a determinação da resistência do aço à tração, e a análise de corrosão nas armaduras. Com essas análises, o técnico pode validar o uso da estrutura ou não.

Apresenta também alguns dos sistemas de proteção passiva presente no mercado e que são mais usuais. Também vale ressaltar a importância e existência de materiais exclusivos para a preparação e construção dessas estruturas, alguns desses materiais são: paredes corta fogo, tintas intumescentes, argamassa projetada contrafogo e por fim o envelopamento por meio de chapas de silicato de cálcio.

Todas essas diretrizes e materiais citados acima são capazes de formar estruturas de concreto resistentes o bastante para impedir e controlar os incêndios, reduzindo e amenizando as consequências por ele provocadas, garantindo assim a integridade da vida humana, da própria estrutura e das edificações localizadas no entorno da estrutura. 


\section{REFERENCIAS BIBLIOGRÁFICAS}

ASSOCIAÇÃO BRASILEIRA DE NORMAS TÉCNICAS. NBR 15200: Projeto de estruturas de concreto em situação de incêndio - Procedimento. São Paulo, 2004. 17 p. >Acesso em: 13 maio 2021.

COSTA, Carla Neves. ESTRUTURAS DE CONCRETO ARMADO EM SITUAÇÃO DE INCÊNDIO. 2002. 21 f. Dissertação (Mestrado) - Curso de Engenharia Estrutural, Engenharia de Estruturas e Fundações, Universidade de Brasília, Brasília, 2002. >Acesso em: 10 maio 2021.

COSTA, C. N. Dimensionamento de elementos de concreto armado em situação de incêndio. 2008. 724f. Tese (Doutorado em engenharia) - Escola Politécnica, Universidade de São Paulo, 2008. >Acesso em: 13 maio 2021.

COSTA, Carla Neves; FIGUEIREDO, Antônio Domingues de; SILVA, Valdir Pignatta. Aspectos tecnológicos dos materiais de concreto em altas temperaturas. NUTA U-USP. São Paulo, 2002. >Acesso em: 08 junho 2021.

CKC. Proteção de Concreto e Alvenaria: CONCRETO E ALVENARIA EXPOSTOS AO FOGO. São Paulo: CKC, 5 ago. 2020. Disponível em: https://www.ckc.com.br/index.php/aplicacoes/272-protecao-de-concreto-ealvenaria.html. >Acesso em: 11 nov. 2021.

CKC. CKC é a escolha dos projetistas, arquitetos, engenheiros e consultores mais renomados do Brasil. São Paulo: CKC, 13 jun. 2020. Disponível em: https://www.ckc.com.br/por-que-escolher-a-ckc. >Acesso em: 10 nov. 2021.

GUARUTHERM. Argamassa projetada contra fogo: Argamassa projetada contra fogo. In: COMERCIAL E ENGENHARIA LTDA, Guarutherm (ed.). Argamassa projetada contra fogo: Argamassa projetada contra fogo. Guarulhos, 19 abr. 2020. Disponível em: https://www.guarutherm.com.br/argamassa-projetada-contrafogo.php. >Acesso em: 06 nov. 2021.

GUARUTHERM. Construção de Parede Corta Fogo: Construção de Parede Corta Fogo. In: COMERCIAL E ENGENHARIA LTDA, Guarutherm (ed.). Construção de Parede Corta Fogo: Construção de Parede Corta Fogo. Guarulhos, 8 mar. 2019. Disponível em: https://www.guarutherm.com.br/construcao-parede-corta-fogo.php. > Acesso em: 11 nov. 2021. 
POY, Luís. Incêndio Parcial em Edifício Comercial com Estrutura em Concreto Armado: A Importância de Testes e Ensaios de Caracterização. Um Estudo de Caso, [S. I.], p. 1-21, 1 fev. 2020. >Acesso em: 10 junho 2021.

PROMAT. Proteção estrutural contra incêndios: por que é importante? proteção passiva contra incêndios. In: PROMAT, (ed.). Proteção estrutural contra incêndios: por que é importante? proteção passiva contra incêndios. São Paulo, 27 abr. 2021. Disponível em: https://www.promat.com/pt-br/construcao/noticias/141969/protecaoestrutural-contra-incendio/. >Acesso em: 11 nov. 2021.

PFC. Argamassa projetada: Cafco 300 e Blaze Shield II. In: PFC. Argamassa projetada: Cafco 300 e Blaze Shield II. São Paulo, 10 ago. 2020. Disponível em: http://www.pcf.com.br/Publicacao.aspx?id=45086. >Acesso em: 11 nov. 2021.

SILVA, V. P. Estrutura de aço em situação de incêndio. Reimpressão. São Paulo: Zigurate, 2004. 249 p. >Acesso em: 12 maio 2021.

SOUSA, Douglas Alves de; SILVA, Guilherme Pereira. ESTRUTURAS DE CONCRETO EM SITUAÇÃO DE INCÊNDIO. 2015. 137 f. TCC (Graduação) - Curso de Engenharia Civil, Universidade Federal de Goiás, Goiânia, 2015. >Acesso em: 16 maio 2021.

TARGET, Equipe. O projeto de estruturas de concreto em situação de incêndio: nbr 15200 de 04/2012: os critérios para as estruturas de concreto em situação de incêndio. NBR 15200 de 04/2012: os critérios para as estruturas de concreto em situação de incêndio. 2018.2 Disponível em: https://patisegnoticias.com.br/2018/03/25/o-projeto-de-estruturas-de-concreto-emsituacao-de-incendio/. >Acesso em: 03 junho 2021.

TAGLIANI, Simone. Incêndios: conheça o sistema passivo de revestimento contra fogo para obras: Uma das preocupações que os projetistas de Arquitetura e Engenharia devem ter é se as suas obras oferecerão segurança para os usuários. In: 360, Engenharia (ed.). Incêndios: conheça o sistema passivo de revestimento contra fogo para obras: Uma das preocupações que os projetistas de Arquitetura e Engenharia devem ter é se as suas obras oferecerão segurança para os usuários. São Paulo, 23 fev. 2021. Disponível em: https://engenharia360.com/incendiosrevestimentos-contra-fogo-para-protecao-estruturas/. >Acesso em: 02 nov. 2021 